\title{
Transportation service bundling - for whose benefit? Consumer valuation of pure bundling in the passenger transportation market
}

\author{
Journal Article \\ Author(s): \\ Guidon, Sergio; Wicki, Michael (10; Bernauer, Thomas; Axhausen, Kay W. (1) \\ Publication date: \\ 2020-01 \\ Permanent link: \\ https://doi.org/10.3929/ethz-b-000337846 \\ Rights / license: \\ In Copyright - Non-Commercial Use Permitted \\ Originally published in: \\ Transportation Research Part A: Policy and Practice 131, https://doi.org/10.1016/j.tra.2019.09.023
}




\title{
Transportation service bundling - for whose benefit? Consumer valuation of pure bundling in the passenger transportation market
}

\author{
Sergio Guidon ${ }^{\mathrm{a}, \mathrm{b}}$, Michael Wicki ${ }^{\mathrm{a}, \mathrm{c}}$, Thomas Bernauer ${ }^{\mathrm{a}, \mathrm{c}}$, Kay Axhausen ${ }^{\mathrm{a}, \mathrm{b}}$ \\ ${ }^{a}$ Institute of Science, Technology and Policy (ISTP), ETH Zürich, Universittstrasse 41, \\ 8092 Zürich, Switzerland \\ ${ }^{b}$ Institute for Transport Planning and Systems (IVT), ETH Zürich, \\ Stefano-Franscini-Platz 5, 8093 Zürich, Switzerland \\ ${ }^{c}$ Center for Comparative and International Studies (CIS), ETH Zürich, Haldeneggsteig \\ 4, 8092 Zürich, Switzerland
}

\begin{abstract}
Novel approaches to service bundling in the passenger transportation market are enabled by technology driven innovations and give rise to so called "Mobility as a Service" (MaaS) concepts. These approaches promise to increase the accessibility of existing public transportation services, possibly decrease car ownership rates and lower the environmental burden of the transportation system. However, the potential effects of comprehensive service bundles in the passenger transportation market are still largely unclear.

In a competitive market, the potential success of MaaS bundles follows consumer valuation of the bundles as compared to valuation of stand-alone services. Thus, the difference between the bundle and sum-of-parts willingness to pay (WTP) is an indicator for the valuation of the bundling itself (which includes service integration valuation) and effects the competitiveness of the service bundles. In this study, several discrete choice experiments were conducted to indirectly estimate consumers' WTP for stand-alone transportation services and service bundles.

The results indicate that public transportation, car-sharing, and park and ride services are valuated significantly higher when offered in a bundle instead of as a stand-alone service. Bicycle-sharing, electrical bicycle (e-bike) sharing and taxi services are valuated lower. Potential consumers also exhibit a high WTP for a smartphone application that integrates the services and manages ticketing and payment.
\end{abstract}

Preprint submitted to Transportation Research Part A (accepted version) April 12, 2019 
Consequently, subscription-based pure bundles for all transportation modes may not be the optimal strategy for mobility providers. Instead, it may be better to bundle public transportation with car-sharing and park and ride to exploit the higher WTP and offer (electric) bicycle-sharing and taxi services on a pay-per-use basis. In this way, profitability of a public transportation system could be increased.

Keywords:

Mobility as a Service, MaaS, willingness to pay, mixed logit, consumer valuation, discrete choice experiment 


\section{Introduction}

Mobility as a service (MaaS) describes the bundling and integration of transportation services in the passenger transportation market into a single coherent service. Service integration is achieved through a digital mobility platform that acts as a gateway, providing a multimodal journey planner or mobility assistant. MaaS can thus be seen as a special case of service bundling, in which integration is achieved through a mobility platform.

MaaS bundles better match supply to demand by closing possible information gaps (e.g. about the spatio-temporal availability of transportation services) and may render multimodal trips more efficient. MaaS is thus expected to decrease transaction costs between mobility providers and consumers. A mobility assistant that analyzes long-term travel behavior could add additional value by personalizing the service. The assistant could provide individuals with suggestions to optimize the journey, while taking personal goals into account (e.g. cost reduction or a recommended distance by foot or bicycle per week). In MaaS bundles with public transportation at the core, efficiency gains could lead to an increased market share for public transportation and a decrease in private vehicle ownership. The associated environmental benefits (through fewer private vehicle-miles travelled) are also in the best interest of the public, as reducing the environmental burden of the transportation system is highly relevant. The integration of services in a service bundle, however, requires a high level of organization and coordination among several mobility providers (which may be in competition with one other). Efficiency gains and the added value of transportation service bundling must clearly outweigh coordination costs. If coordination costs are higher than the efficiency gains and the added value, it would not be profitable to offer MaaS bundles.

Bundling has been the focus of a rich economic literature, especially in the subfields of production economics and marketing. Examples for bundling are the combination of an airline ticket with a car rental option at the destination or software bundles such as Microsoft Office. Bundling of products and services can result in numerous advantages for firms, as bundling can serve as a measure to implement corporate strategies (e.g. to introduce new products or to deter competitors from entering a market). Under certain conditions, bundling can also be an effective tool for price discrimination when knowledge about consumer preferences is limited (McAfee et al., 1989, Sheikhzadeh and Elahi, 2013; Vamosiu, 2018). For MaaS bundles, the goal, 
in most cases, is not a vertical integration by a monopoly provider, but an integration of mobility services across different mobility providers (which may be in competition with one other). Whether consumers valuate a bundle higher than the sum of its parts depends on whether bundling and service integration is viewed as performance enhancing. The difference in valuation between MaaS bundles and sum-of-parts is of key importance to profitability and the competitive positioning compared to existing stand-alone services. In a competitive market, the success of transportation service bundles may be determined by this difference in valuation. Knowledge about the valuation difference is therefore highly relevant.

In order to investigate how consumers valuate transportation services and service bundles, an online survey was conducted in the canton of Zurich in May 2018. The introductory part of the survey gathered information about study participants' demand for mobility, current consumption of mobility services, ownership and usage of mobility tools, personal mobility budget, socio-demographic information and attitudes toward public transportation, cycling and car-ownership. Several discrete choice experiments (DCE) were embedded in the survey: for each transportation service, a DCE was conducted to estimate indirectly the willingness to pay (WTP). The WTP for service bundles containing the same services were also determined in a separate DCE in order to be able to calculate the WTP differences and thus, the consumers' valuation of bundling and service integration. The experiment allows for the following questions to be answered: Is there a perceived utility of the mobility platform; i.e. the smartphone application? Do consumers view the bundling of transportation services as utility enhancing? Are consumers more likely to consume new mobility services (such as park and ride or bicycle-sharing) when offered in a bundle? The analysis also reveals which mobility services are perceived as complements or substitutes and thus provides an indication of which services should be offered together.

\section{Background}

\subsection{MaaS as a Concept and the Definition of MaaS}

The term "Mobility as a Service" has been used to describe a special case of service bundling in the passenger transportation market. It was introduced in a Master's thesis for the city of Helsinki by Heikkilä (2014) and investigated the potential of information and communications technology (ICT) to make the transportation system more efficient. MaaS was originally defined 
as "a system, in which a comprehensive range of mobility services are provided to customers by mobility operators" (Heikkilä, 2014). This system would therefore be a service itself. MaaS, as a term, has since been widely accepted by most transportation researchers. However, a consistent, universally accepted definition of when a service can be regarded as "MaaS" is still lacking. Thus, the concept and its relationship to traditional public transportation is discussed first.

Based on a comprehensive literature review, Jittrapirom et al. (2017) identify nine core characteristics of MaaS. Among others, the characteristics include the integration of transportation modes, a digital platform and the existence of two tariff options (pay-as-you-go and subscription-based). However, the authors provide no indication as to which combination of these characteristics are necessary and sufficient conditions for a MaaS service. Kamargianni et al. (2016) state that MaaS is based on three main elements: ticket and payment integration, the mobility package and ICT integration. But, with these three elements, it also remains unclear which of them are necessary and sufficient conditions. It is clear that ticket and payment integration is necessary to provide customer-friendly service bundling and that the use of modern ICT applications with location-based services (LBS) are key to the concept. It is unclear, however, how the "mobility package" (described as the ability to prepay services) is a main element. Prepayment is not a necessary condition, as customers could also be charged by credit card or by monthly bill (in practice, the UbiGo users even found prepayment to be a limitation of the service (Sochor et al., 2014)). Hensher (2017) defined MaaS as a service that "combines transportation services from public and private transportation providers through a unified gateway that creates and manages the trip, which users can pay for with a single account". This definition is concise and stresses bundling, while avoiding unnecessary elements such as prepayment. The definition also excludes single services without bundling (e.g. Uber) and avoids ambiguity and its consequences (e.g. a shift away from privately owned vehicles). The definition makes the two necessary and sufficient conditions of MaaS apparent: 1) transportation service bundling and 2) a mobility platform (with a multimodal journey planner) that acts as a unified gateway (the ability to pay with a single account, i.e. payment integration, is implied in service bundling). This definition is also consistent with Transport Systems Catapult (2016), where a digital mobility platform is considered the core innovation of MaaS. Pricing of a MaaS service may be subscription-based or on a pay-per-use basis (it is, however, a bundle 
in either case).

The potential utility of ICT-based transportation service bundles is apparent: the ICT system that provides the gateway to the bundled transportation services increases accessibility of those services by providing information about spatio-temporal availability that is tailored to the customer's location. On a software-level, such services are commonly referred to as location-based services (LBS), which are clearly at the core of MaaS bundles. The ICT system should also be able to identify possible transportation options or a combination thereof, as well as additional details, such as trip time and cost. In the future, the market may also increasingly adopt Internet of Things (IoT) solutions that may render the interaction between transportation services and the user more efficient and comfortable (e.g. such that the user interaction time is minimized). Examples of this include more efficient automated check-ins for public transportation vehicles (e.g. for pricing purposes) that do not solely rely on GPS data provided by the user, or the consideration of battery charging levels of shared electric vehicles or e-bikes by the mobility platform.

\subsection{Service Bundling in Production Economics and Marketing}

MaaS can be seen as a special case of service bundling and there is a vast body of literature on bundling in the fields of production economics and marketing that is also relevant for the passenger transportation market. This is not surprising, as product and service bundling is common practice in several industries, including airlines, telecommunications and IT. As service integration is central to service bundling, ICT solutions are naturally used when conducive to the integration process. Previous research also provides accurate and concise terminology for different types of product and service bundles. Investigated topics have included the role of complementarity and substitutability of the bundled services (McAfee et al., 1989; Yan et al., 2014), as well as optimal bundling strategies in different competitive situations; i.e. perfect and imperfect competition (Adams and Yellen, 1976, Vamosiu, 2018). The incentive to bundle when consumers' valuation are non-additive (Armstrong, 2013), the implications of bundling on marketing (Stremersch and Tellis, 2002) and bundling as an instrument to deter competitors from entering a market (Eppen et al., 1991) have also been investigated. Other studies have looked into bundling for specific industries (Hui et al., 2012; Sobolewski and Kopczewski, 2017). Sobolewski and Kopczewski (2017), for example, investigated complementarity and substitutability of service components in 
telecommunication bundles. The authors also investigate the WTP of standalone services versus bundled services through direct questions in a survey. This approach is problematic though, as it is difficult for participants to express their own WTP and the resulting estimates may be highly biased. It has been shown that for WTP estimation, indirect survey techniques provide better results (Breidert et al., 2006).

A clear definition of bundling terms and strategies is provided by Stremersch and Tellis (2002, p. 57). They define bundling as "...the sale of two or more separate products in one package". The two main dimensions of bundling are price bundling and product bundling. Price bundling is "the sale of two or more separate products as a package at a discount, without any integration of the products". Product bundling refers to the integration of the products at any price. Another important classification is between "pure bundles" and "mixed bundles." Pure bundling refers to a situation where a firm only sells bundles and the bundled products are not offered separately. In a mixed bundle, the products can also be purchased separately (Stremersch and Tellis, 2002). These two dimensions of bundling could also be used in transportation research to classify bundles in the passenger transportation market. The legality and optimality of bundling strategies, the effect of competition on the bundling decision, and consumers' perception of bundles are also discussed in Stremersch and Tellis (2002). These issues have not yet been investigated for the case of transportation service bundles and therefore, are still unclear.

The theoretical foundation of behavioral bundling research and investigations into the likelihood of purchase are particularly relevant for a consumer valuation study. Stremersch and Tellis (2002) show that behavioral research on bundling is rooted in prospect theory (Kahneman and Tversky, 1979) and mental accounting (Thaler, 1985). Price sensitivity decreases and purchase likelihood increases when consumers are presented with a single bundle price instead of a list of prices (Drumwright, 1992; Gaeth et al., 1990; Yadav, 1994). Thus, the "menu plan" (mixed bundle) investigated by Matyas and Kamargianni (2017) for transportation services would not be an optimal strategy for firms. Consumers perceive a list of prices as multiple losses, which negatively affects purchase likelihood. This also implies that price sensitivity for a bundle should be lower than for the sum of the prices of the stand-alone services. Furthermore, Eppen et al. (1991) show that product and service bundling can be used as a strategy to introduce new products. In the transportation market, this could be used for the introduction of new 
transportation options, such as bicycle-sharing or car-sharing (Matyas and Kamargianni, 2018).

\subsection{MaaS Literature Review}

Existing literature in transportation research was grouped into three main streams: a) case studies of trials of MaaS bundles, b) DCEs investigating consumer demand for hypothetical MaaS bundles and c) discussions of potential consequences from MaaS on the transportation system.

Although only a few MaaS schemes are well documented in the academic literature, there have been a number of trials of integrated transportation systems in several countries and regions. Kamargianni et al. (2016) assess several integrated mobility schemes with regard to the level of integration along three dimensions: ticket and payment, prepayment option ("mobility package") and ICT integration. Several operational systems with a high integration level were identified: Hannovermobil, EMME in Montpellier, and three systems in the Netherlands that are directed at business travelers (Mixx, NS-Business, Radiuz Total Mobility). SHIFT in Las Vegas, UbiGo in Gothenburg, and the Helsinki model were listed as highly integrated systems that offer a prepayment option. Further, an integration measure and ranking system were also constructed within this study. The categories of "ticket integration", "payment integration", "ICT integration", and "mobility package integration" were equally weighted for the integration measure.

One of the systems that has been classified as highly integrated and that is well documented is UbiGo. Sochor et al. (2014) and Sochor et al. (2016) investigate the case of UbiGo, one of the first operational trials of an integrated mobility service. Sochor et al. (2014) assess the factors motivating and hindering adoption using a mixed methods approach that included surveys, interviews, focus groups and workshops. The results show that users' motivation for participating in the operational trial in the first place was merely curiosity. Curiosity was replaced by convenience, flexibility and economic considerations as the study progressed. This is expected, as curiosity naturally fades, and as the study unfolded, the convenience and price could be better assessed. Incentive systems, where awarded points could be used for sponsor services, only played a minor role and could not compensate for economic disadvantages. Factors hindering user adoption were the price (more expensive than current mobility choices), the accessibility of alternative transportation options, and not enough demand for mobility services (Sochor et al., 2014). The case of UbiGo is an important source of 
information for future investigations of the market potential of MaaS bundles. Sochor et al. (2016) further assess changes in travel behaviour during the UbiGo trial. An increase in car-sharing, bicycle-sharing and traditional public transportation was observed, while the share of trips by private car decreased. This provides first indications that MaaS bundles could indeed decrease the environmental burden of the transport system.

The positive reports of early MaaS trials have sparked interest in MaaS and its market potential. A way to investigate the market potential in hypothetical markets are stated preference (SP) experiments. Matyas and Kamargianni (2017) conducted a SP experiment to investigate the choice process of purchasing transportation service bundles. Study participants were presented with three "fixed" bundles (which in marketing terms would be called "pure bundles") and a "menu option" (a mixed bundle). The bundles included public transportation, bicycle-sharing, taxi, as well as car-sharing. Additional features were also included; e.g. access to a minivan in the carsharing option, or a 10 minute pickup guarantee for the taxi service. The survey process included an introductory survey, GPS tracking and a survey after tracking for the SP experiment. In the experiment, each respondent was presented with four choice tasks. In total, 80 participants completed the whole survey, including the SP experiment. The results were analyzed using a multinomial logit model (MNL) that included 236 choice observations. Public transportation was found to be the core element of transportation service bundles (Matyas and Kamargianni, 2017). However, future work will have to take some of the limitations of the study into account. First, the authors recommend more advanced modelling for future studies. Indeed, an MNL was not the correct choice given that each respondent completed four choice tasks. The data most likely exhibited correlations of unobserved factors of the decision makers and the MNL would not be suitable in this case. Second, there was no investigation of the WTP for the elements of the bundles (this would be a natural extension when price is an attribute). Finally, it is unclear if the GPS tracking of the subjects was necessary for investigating transportation service bundling. GPS tracking requires significant effort (i.e. recruitment, data cleaning etc.) and therefore, the sample size is often limited. Reproducibility of a study also suffers in these cases because the tools are often not openly available and are not standardized. A travel diary or survey is sufficient to collect information about current mobility behavior in most cases. However, the general questions on how MaaS bundles should be designed and which transportation services should be included are in- 
teresting and important given the potential effects of transportation service bundling on the wider transportation system. It would be worthwhile to conduct similar studies in several countries in order to gain robust insights into the potential of service bundling in the transportation market.

Matyas and Kamargianni (2018) investigate the question of whether MaaS bundles could serve as a mobility management tool to promote shared modes. The authors find that the presence of shared modes decreased study participants' probability of choosing a MaaS plan. Yet, traditional public transportation increased the choice probability. A second model that only included participants that indicated that they would subscribe to their chosen plan confirmed the results of the full sample. Furthermore, a majority of study participants who considered subscribing to a MaaS bundle agreed with the statement that they would be willing to try transportation modes that they previously haven't used. This led to the conclusion that MaaS bundles could, nevertheless, be used as a mobility management tool (Matyas and Kamargianni, 2018). The observation that shared modes even provided negative utility to participants that considered subscribing to a MaaS bundle (which included them) is interesting and seems counterintuitive. Given that all these services could also be bought as stand-alone services, the behavior even seems irrational. A potential explanation could be that this subsample exhibited a low price sensitivity (e.g. due to above average income), which may have led to a preference for a more "carefree" solution that included access to all modes. A more straightforward explanation could be survey bias and the fact that participants have not considered that they could also buy the services as stand-alone. Future studies are thus needed to conclude whether MaaS bundles could indeed serve as a mobility management tool.

Ho et al. (2018) report the results of a study on the potential uptake and WTP for a MaaS service in Sydney. Their results suggest that people that are presently not using a car and very frequent car users ( 5 to 7 days per week) are less likely than average to choose a MaaS plan. However, infrequent car users ( 1 or 2 days per week) and frequent cars users (3 to 4 days per week) were more likely to take up a MaaS plan. The authors explain the results with the fact that car nonusers are often also frequent public transportation users and that these users are seemingly satisfied with their current season ticket (Ho et al., 2018). However, the findings may also reveal a deeper connection between the propensity of choosing a MaaS plan and long-term mobility choices. Frequent public transportation users may live in areas where public transportation accessibility is high and thus 
they may also be able to reach most (if not all) daily activities with public transportation. This could mean that a car-sharing, an uberPool or even a taxi subscription may simply not be attractive for them. This may be even more the case if they have access to a private car (e.g. through family members) to perform extraordinary trips. Future studies could consider this by taking public transportation accessibility and access to a private car (not only ownership and usage) into account.

The survey experiments in London and Sydney provide first insights into the market potential of MaaS. However, as MaaS has still not been put into practice in many places, the effects on the wider transportation system remain unclear. In a think piece, Hensher (2017) discusses potential effects taking into account a number of challenges MaaS has to overcome. The author puts a special focus on the implications of MaaS on future bus services and their integration with point-to-point services. It is likely that several transportation services will coexist in the future, and bundling will complement the landscape of services. The author also argues that there are contexts where bundling may not be appropriate (such as school bus services). When MaaS is scaled up, the broker role in the passenger transportation market could become more important (Hensher, 2017). Given the limited information, it seems too early to speculate on the possible effects of bundling on modal shares or car ownership. However, it is conceivable that vehicle sharing as a part of transportation service bundles may indeed lead to more efficient utilization of existing infrastructure if MaaS bundles are able to increase their usage (as suggested by Matyas and Kamargianni (2018)). This, of course, highly depends on the services that are part of the bundles. The question of scalability must also be addressed in more detail in order to make informed claims about mode shifts and car ownership.

\subsection{Research Gap and Contributions}

Existing literature on MaaS reveals that the market potential of MaaS, the design of the service bundles and the overall effect on the wider transportation system is still unclear. Previous survey experiments have mainly focused on the influence of sociodemographic and household characteristics on the adoption of MaaS plans and customers' WTP. However, a central question that will most likely determine the potential success of MaaS bundles has not been answered yet. In a competitive market, where public transportation services can also be purchased as stand-alone services, the potential success of MaaS bundles follows consumer valuation of the bundles as compared to the 
sum of the valuations of the respective stand-alone services. The difference in these valuations can be seen as the valuation of bundling. This paper thus seeks to determine the difference between bundle and sum-of-parts WTP to determine bundling valuation. In addition, the WTP of services within a bundle can also be an indication of which services should be offered together. The results aim to contribute to the discussion of the profitability of MaaS and could assist with design decisions concerning MaaS bundles in practice.

\section{Methods}

\subsection{Survey Instrument}

In order to investigate ICT-based transportation service bundling, an online survey was conducted in the canton of Zurich, Switzerland 1 . The survey consisted of an introductory part, six DCEs for transportation services in the canton as stand-alone, and one DCE for a mobility service bundle that included the same services as the first six DCEs. The last part of the survey was a 12-item measure for technological commitment (Neyer et al., 2016) and a nine-item scale to capture environmental attitudes (Diekmann et al. 2009). All participants were asked to complete the whole survey. The first part of the survey contained questions on sociodemographics, participants' current consumption of mobility services, kilometers driven by private car and current mobility expenditures. The survey instrument was designed such that the average response time did not exceed 30 minutes.

The survey was geographically constrained to the canton of Zurich, Switzerland, in order to ensure that all participants faced the same options for mobility (each canton usually has its own local public transport providers with different pricing schemes). Participants were recruited by a private company, Intervista 2 , which maintains a panel of registered persons who have consented to participating in surveys. The survey was completed by 1000 participants with a response rate of $23.6 \%$. Quotas were set on age, education, gender and public transportation season ticket ownership, such that the sample was comparable to the population of the canton of Zurich in the Swiss household

\footnotetext{
${ }^{1}$ The canton of Zurich has a population of approximately 1.5 million people. With a population density of approximately 860 persons $/ \mathrm{km}^{2}$, the canton is mostly urbanized, but also includes rural parts.

${ }^{2}$ Company website: https://survey.intervista.ch/, last accessed: July 2018.
} 
travel survey "Mikrozensus Mobilität und Verkehr" (MZMV) (Swiss Federal Statistical Office (BFS), 2017).

Table 1 shows a comparison of a selected set of variables of this survey with the MZMV, as well as a chi-square goodness of fit test (H0: the survey sample is consistent with the MZMV). Overall, the population of the canton of Zurich is well represented by the survey sample. When considering the sociodemographic attributes of gender and income, the two samples are very similar. A slight deviation of the age distribution can be observed, especially the age group of 51 to 65 is slightly overrepresented (by 3.2\%). Driver's license holders were also slightly overrepresented in this survey (by 4.6\%), as well as holders of the GA travel card from the national train company (SBB) that allows unrestricted travel access on all public transportation networks (by $3.9 \%$ ). Holders of the cantonal season ticket were underrepresented (by $5 \%)$.

Table 1: Comparison of survey sample with the Swiss household travel survey (MZMV 2015)

\begin{tabular}{|c|c|c|c|c|}
\hline Variable & Level & Survey & $\begin{array}{l}\text { MZMV } 2015 \\
\text { (Ct Zürich) }\end{array}$ & $\begin{array}{c}\text { Chi Square } \\
\text { Goodness of Fit } \\
\text { (p-value) }\end{array}$ \\
\hline Sex & Male & $49.1 \%$ & $50.6 \%$ & 0.33 \\
\hline Age & $\begin{array}{l}18-35 \\
36-50 \\
51-65 \\
66+\end{array}$ & $\begin{array}{l}25.5 \% \\
29.1 \% \\
24.0 \% \\
21.4 \%\end{array}$ & $\begin{array}{l}27.5 \% \\
30.4 \% \\
20.8 \% \\
21.3 \%\end{array}$ & 0.10 \\
\hline $\begin{array}{l}\text { Income/mo }[\mathrm{CHF}] \\
\text { (household) }\end{array}$ & $\begin{array}{l}\text { Below } 4000 \\
4^{\prime} 001-8^{\prime} 000 \\
\text { 8'001 - 12'000 } \\
\text { More than } 12000\end{array}$ & $\begin{array}{l}17.5 \% \\
40.0 \% \\
23.8 \% \\
18.7 \%\end{array}$ & $\begin{array}{l}18.0 \% \\
40.3 \% \\
23.5 \% \\
18.2 \%\end{array}$ & 0.94 \\
\hline Driver's license & Yes & $86.0 \%$ & $81.4 \%$ & $<0.001$ \\
\hline $\begin{array}{l}\text { Half-fare card } \\
\text { GA travel card } \\
\text { Season ticket Ct Zurich } \\
\text { None }\end{array}$ & Yes & $\begin{array}{l}48.3 \% \\
15.7 \% \\
19.2 \% \\
31.1 \%\end{array}$ & $\begin{array}{l}47.5 \% \\
11.8 \% \\
24.2 \% \\
30.0 \%\end{array}$ & $\begin{array}{c}0.65 \\
<0.001 \\
<0.001 \\
0.14\end{array}$ \\
\hline
\end{tabular}




\subsection{DCE Design}

Table 2 shows the attributes and attribute levels of the DCEs for the stand-alone transportation services, and Table 3 shows the service bundles. All choice tasks included an opt-out option (i.e. a way to decline the offer) and the designs were constrained in order to exclude unreasonable prices. The values in a DCE are a design choice and should be as realistic as possible. It would, for example, not make sense to offer the option of a public transportation season ticket for the whole country for CHF 20 when it is priced at CHF 340 in the real market. For all experiments, D-optimal designs were constructed with the software "NGENE" 3 (Rose et al., 2014). Each experiment for the stand-alone services included two attributes: the cost and a description of the extent (minutes travelled, kilometers, etc.). For the stand-alone services, the respective price ranges were derived from real market prices in the canton. Costs were denoted in Swiss francs (CHF) (1 $\mathrm{CHF} \approx 1$ USD or $0.85 \mathrm{EUR}$ as of May 2018) and an example for the choice situations is shown in Figure 1. The wording of the introductory texts for the DCEs can be found in the Appendix.

For public transportation, the second attribute is the number of zones 4 (i.e. geographical units for pricing purposes). The price for season tickets in the canton increases linearly with the number of included zones (CHF 30 per additional zone for a second class ticket). The price was capped at five zones because tickets with more than five zones are valid in the whole canton. The GA travelcard is valid for the whole country. Real market prices for monthly season tickets range from $\mathrm{CHF} 65$ to $550^{5}$, and the prices in the experiment ranged from CHF 20 to 650.

The car-sharing service included a prespecified number of kilometers per month. The local car-sharing company "Mobility" charges by time and distance. Only distance was chosen as a measure to simplify the experiment and because it is the main cost driver of the service. Constraints were imposed on the design such that the displayed attribute levels imply a cost per

\footnotetext{
${ }^{3}$ As no priors were available, the designs were created with priors of zero (naive priors). It has to be noted that a random design may have performed equally well or better under these conditions (Walker et al., 2018).

${ }^{4}$ Public transportation services in the canton of Zurich are united in a public transportation association, "ZVV". ZVV offers season tickets that are valid for a certain number of zones. Within the purchased zones, all public transportation services can be used.

${ }^{5}$ See https://www.zvv.ch/ and https://www.sbb.ch/ for price information.
} 
kilometer of $0.4-2.8 \mathrm{CHF} / \mathrm{km}$. The local car-sharing company charges from CHF 0.55 to $1.05 \mathrm{CHF} / \mathrm{km}$ (depending on the type of car). The cost was higher in the experiment in order to cover a higher WTP range and because time was ignored as a factor.

Bicycle-sharing was included as a monthly subscription service, with cost and included hours per month as attributes. Two free-floating bicycle-sharing companies, "LimeBike" and "O-Bike", were active in Zurich in May 2018 with prices of CHF 2 and CHF 3 per hour. PubliBike, a station-based service, was priced at CHF 6 per hour (without annual subscription). CHF $1.4-6.7$ was chosen as the range of implied prices for the experiment.

E-bike-sharing in Zurich is provided by two companies, "PubliBike" and "Smide," the latter being a free-floating system directed at the high-end market (and only available in the city of Zurich, not in the whole canton). Without a subscription, prices ranged from CHF 9 - 15 per hour. CHF 5 - 43 per hour was chosen for the experiment. E-bike-sharing was separated from traditional bicycle-sharing as the electric motorization allows for higher speeds and longer distances and it may be used by different customer groups, such as commuters (Guidon et al., 2018).

The park and ride service in the experiment included a prespecified number of days at all SBB train stations. Park and ride parking spots in the canton of Zurich that were included cost CHF 0 - 15 per day and the attribute levels implied prices of CHF 1.4 - 14.2 per day.

The price per minute for taxi services in Zurich ranges from CHF 1 (UberX) to CHF 2.5 (Uber Black, which is comparable to other taxi services). Thus, the prices in the experiment range from $\mathrm{CHF} 0.5$ to $\mathrm{CHF} 5$. Uber was not separated from traditional taxi services because the prices and the provided service are very similar in Zurich (due to regulatory constraints Uber Pop and pooled services are not available). In other regulatory environments, a separation of Uber and traditional taxis could be considered.

The car-sharing and park and ride experiments were only displayed to study participants with a driver's license. For the bundles, the car-sharing and the park and ride attribute were interacted with driver's license ownership in the statistical model in order to make the WTP values comparable.

Table 3 shows the attributes and attribute levels of the DCE for transportation service bundles. Participants completed 18 choice tasks. The number of attribute levels was reduced compared to the stand-alone experiments to limit the number of choice tasks (in order to limit the total response burden of the survey). All participants were asked to complete all tasks of the 
Table 2: DCEs for stand-alone transportation services: attributes and attribute levels. All participants completed all DCEs, while participants without driver's license were excluded from the DCE for park and ride and car-sharing.

\begin{tabular}{llll} 
Experiment & Attributes & Levels & \# Choice tasks \\
\hline \multirow{2}{*}{ 1. Public transportation } & Cost $(\mathrm{CHF} / \mathrm{mo})$ & $50,120,180,240$, & \multirow{2}{*}{18} \\
& Validity $(\mathrm{level})$ & $1-2,300,4,5,5$, all, GA & \\
\hline \multirow{2}{*}{ 2. Car-sharing } & Cost $(\mathrm{CHF} / \mathrm{mo})$ & $30,70,100,200,350$ & 10 \\
& Kilometres included & $50,75,125,150$ & \\
\hline 3. Park and Ride & Cost $(\mathrm{CHF} / \mathrm{mo})$ & $10,20,50,100,150,200$ & 12 \\
& Days $/ \mathrm{mo}$ & $4,7,14$ & \\
\hline \multirow{2}{*}{ 4. Bicycle-sharing } & Cost $(\mathrm{CHF} / \mathrm{mo})$ & $5,10,20,30,40,60$ & 12 \\
& Hours $/ \mathrm{mo}$ included & $3,5,7,10$ & \\
\hline 5. E-bike-sharing & Cost $(\mathrm{CHF} / \mathrm{mo})$ & $20,60,100,150,200,300$ & 12 \\
& Hours $/ \mathrm{mo}$ included & $3,5,7,10$ & \\
\hline 6. Taxi & Cost $(\mathrm{CHF} / \mathrm{mo})$ & $15,30,60,150,300,600$ & 12 \\
& Minutes $/ \mathrm{mo}$ included & $30,60,120$ & \\
\hline
\end{tabular}

bundle choice experiment.

Table 3: DCE for transportation service bundles (pure bundles): attributes and levels.

\begin{tabular}{llll} 
Experiment & Attributes & Unit & Levels \\
\hline Bundle & Cost & CHF/mo & $150,200,300,400,900,1800$ \\
& Smartphone App & Dummy & 0,1 \\
& Public Transportation & Validity (zones) & $1-2,3,4,5$, all, GA \\
& Car-sharing & Kilometres included & 50,125 \\
& Park and Ride & Days/mo & 7,14 \\
& Bicycle-sharing & Hours/mo included & 3,5 \\
& E-bike-sharing & Hours/mo included & 3,5 \\
& Taxi & Minutes/mo included & 30,60 \\
\hline
\end{tabular}




\begin{tabular}{|c|c|c|}
\hline \multicolumn{3}{|c|}{ Example e-bike-sharing } \\
\hline & Option 1 & Option 2 \\
\hline $\begin{array}{l}\text { Cost } \\
\text { (per month) }\end{array}$ & CHF 20 & CHF 100 \\
\hline $\begin{array}{l}\text { Hours } \\
\text { (per month) }\end{array}$ & $3 \mathrm{~h}$ & $10 \mathrm{~h}$ \\
\hline \multicolumn{3}{|l|}{ Selection } \\
\hline Option 1 & & \\
\hline Option 2 & & \\
\hline Decline & & \\
\hline
\end{tabular}

\begin{tabular}{|c|c|c|}
\hline \multicolumn{3}{|l|}{ Example bundle } \\
\hline & Option 1 & Option 2 \\
\hline $\begin{array}{l}\text { Cost } \\
\text { (per month) }\end{array}$ & CHF 400 & CHF 300 \\
\hline Smartphone App & Yes & No \\
\hline $\begin{array}{l}\text { PT Subscription } \\
\text { ( } 2^{\text {nd }} \text { class) }\end{array}$ & ZVV 4 zones & ZVV all zones \\
\hline $\begin{array}{l}\text { Car-sharing } \\
\text { (km per month) }\end{array}$ & $125 \mathrm{~km}$ & $50 \mathrm{~km}$ \\
\hline $\begin{array}{l}\text { Bike-sharing } \\
\text { (hours per month) }\end{array}$ & $5 \mathrm{~h}$ & $3 \mathrm{~h}$ \\
\hline $\begin{array}{l}\text { E-bike-sharing } \\
\text { (hours per month) }\end{array}$ & $3 \mathrm{~h}$ & $5 \mathrm{~h}$ \\
\hline $\begin{array}{l}\text { Parking } \\
\text { (hours per month) }\end{array}$ & 7 days & 14 days \\
\hline $\begin{array}{l}\text { Taxi subscription } \\
\text { (min per month) }\end{array}$ & $60 \mathrm{~min}$ & $30 \mathrm{~min}$ \\
\hline \multicolumn{3}{|l|}{ Selection } \\
\hline Option 1 & & \\
\hline Option 2 & & \\
\hline Decline & & \\
\hline
\end{tabular}

Figure 1: Example choice situations for individual services (a) and service bundles (b).

\subsection{Statistical Modelling}

To analyze the results of the experiment, a mixed logit model was used. The advantage of mixed logit is that it does not exhibit the restrictive independence of the irrelevant alternatives property and can be generalized to accommodate repeated choices by decision makers. Thus, correlations of unobserved factors from the decision makers can also be accommodated. As shown by Train (2009), correlations of unobserved factors of the decisions makers can be taken into account by letting coefficients vary over decision makers, but not over choice situations. Thus, the utility of an alternative $j$ for decision maker $n$ in choice situation $t$ can be expressed as $U_{n j t}=\beta_{n} x_{n j t}+\epsilon_{n j t}$. The conditional likelihood that a participant makes a sequence of choices in time periods $\boldsymbol{i}=\left\{i_{i}, \ldots, i_{T}\right\}$ can then be written as $L_{n i}(\beta)=\prod_{t=1}^{T}\left[\frac{e^{\beta_{n} x_{n i} t}}{\sum_{j} e^{\beta_{n} x_{n j t}}}\right]$ and the unconditional probability is $P_{n \boldsymbol{i}}=\int L_{n \boldsymbol{i}}(\beta) f(\beta) d \beta$.

Seven mixed logit models were estimated: one for each of the six standalone services and one bundle model. Socio-demographic variables were not added to the model as the goal was to investigate valuation differences between bundles and stand-alone services and not the investigation of the effects 
of socio-demographic and household characteristic: 6 . However, investigating the effects of socio-demographic and household characteristics on the choice of MaaS bundles is important for the identification of potential customer groups and will be subject to future research.

\subsection{WTP Calculation}

The estimation of the WTP in the case of the mixed logit model is not as straightforward as in the multinomial logit case, as the parameters are random variables. Sillano and Ortúzar (2005) discuss two methods for estimating the WTP: using the ratio of population means and simulation. The authors also discuss two further approaches to obtain consistent signs for the WTP values and increase the stability of the estimates: using a log-normal distribution for parameters and fixing the cost coefficient.

Taking the ratio of population means does not result in a mean WTP value. Instead it results in a WTP for the average individual and thus the approach is only recommended to test the model specification. The simulation approach involves taking random draws from the parameters' distributions, calculating the ratio, and repeating the process many times to sample the WTP distribution. The spread of the WTP distribution obtained by simulation can be very large and thus, researchers often constrain the distribution in practice (Sillano and Ortúzar, 2005). Hensher and Greene (2003) showed that there is no behavioral justification for constraining the distribution except for the sign of the WTP and that using the constrained distribution is not better or worse than using the unconstrained distribution. Sillano and Ortúzar (2005) criticize the approach not because of this issue, but because of the fact that values are simulated for people that do not exist in the first place.

In order to obtain consistent signs for the WTP values, many previous authors have used log-normal distributions for parameters over the population. However, Sillano and Ortúzar (2005) do not recommend using log-normal distributions as it tends to result in very large WTP values.

In the models estimated by Sillano and Ortúzar (2005), fixing the cost coefficient led to an overestimation of the WTP distribution. However, Revelt and Train (2000) put forward the following arguments for fixing the cost

\footnotetext{
${ }^{6}$ For a discussion about the effects of socio-demographic and household on the choice of MaaS bundles refer to Ho et al. (2018) and Matyas and Kamargianni (2018).
} 
coefficient: 1) mixed logit models tend to be unstable when all parameters are random, 2) with a fixed price coefficient, coefficient ratios follow the same distribution as the coefficient of the attribute, and 3) as the price coefficient is necessarily negative, the choice of the respective distribution can be problematic (a log-normal distribution may result in extremely high WTP values).

Another approach is to estimate models directly in the WTP space instead of the preference space and thus obtain the WTP directly as an output of the model estimation. The concept was first introduced by Cameron and James (1987) and Cameron (1988) and was later investigated in Train and Weeks (2005). Train and Weeks (2005) found that models in preference space fit the data better, but models in the WTP space resulted in more reasonable distributions of WTP.

In this paper, a fixed cost coefficient was used and thus, the WTP distribution was derived from the distributions of the non-cost coefficients. The mean and standard deviation of the WTP distribution are the mean and standard deviation of the non-cost coefficient divided by the cost coefficient. A disadvantage of the approach is that the standard deviation of unobserved utility (i.e. the scale) is considered the same for all observations. This may bias conclusions concerning the WTP because variation in scale may be attributed to variation in WTP (Train and Weeks, 2005). However, the reason for using a fixed cost coefficient in this study was the greater stability of the models (a consistent and robust method was required to estimate all seven DCE models.) 


\section{Results}

\subsection{Model Estimation: Stand-Alone Services and Bundled Services}

Table 4 shows the result of the mixed logit model estimations for the stand-alone transportation services. The cost coefficient was fixed, and the coefficients describing the respective extent of service and the opt-out coefficient were assumed to follow a normal distribution. The cost coefficients were negative for all experiments, which was expected. The coefficients for the respective services were all positive, except for the taxi subscription. Positive coefficients were expected, as a higher extent of service should increase the choice probability. The standard deviations of the coefficients were significant and substantial, which indicates high taste heterogeneity between subjects. The model fit compared to the null model was good for public transportation (pseudo $R^{2}$ of 0.38 ), and very good for the other services (pseudo $R^{2}$ greater than 0.5 for all services).

Table 5 shows the estimation results for the transportation service bundles. The coefficients for the extent of service were positive for the smartphone application, public transportation, car-sharing and park and ride, which was expected. For bicycle-sharing, e-bike-sharing and taxi, the coefficients were negative. The cost coefficient was negative and significant as well. The standard deviations of the coefficients were significant and substantive for the smartphone app, public transportation and bicycle-sharing. For car-sharing, e-bike-sharing, park and ride and taxi, they were not significant. The model fit was very good, with a pseudo $R^{2}$ of 0.62 .

The number of respondents in Table 4 and 5 corresponds to the number of participants who have completed all choice tasks of the respective choice experiment. "Opt-out rate" designates the opt-out rate over all choice tasks and "opt-out all" the share of individuals who have opted out at all choice tasks. It can be observed that the share of individuals who have opted out of all public transport offers is very low (8.4\%). Interestingly, the share of individuals who have opted out of all bundle offers $(31.8 \%)$ is substantially lower than the shares of individuals who have opted out of shared modes, park and ride and taxi (between $42.4 \%$ and $55.3 \%$ ). 
Table 4: Model estimates for stand-alone services (mixed logit). "Opt-out rate" at the bottom of the table designates the opt-out rate over all choice tasks of the experiment, "opt-out all" the share of individuals who have opted out at all choice tasks.

\begin{tabular}{|c|c|c|c|c|c|c|}
\hline & $\mathrm{PT}$ & $\begin{array}{c}\text { Car- } \\
\text { sharing }\end{array}$ & $\begin{array}{l}\text { Bicycle- } \\
\text { sharing }\end{array}$ & $\begin{array}{l}\text { E-bike- } \\
\text { sharing }\end{array}$ & $\begin{array}{c}\text { Park and } \\
\text { Ride }\end{array}$ & Taxi \\
\hline Cost & $\begin{array}{c}-0.01^{* * *} \\
(0.00)\end{array}$ & $\begin{array}{c}-0.02^{* * *} \\
(0.00)\end{array}$ & $\begin{array}{c}-0.14^{* * *} \\
(0.01)\end{array}$ & $\begin{array}{c}-0.03^{* * *} \\
(0.00)\end{array}$ & $\begin{array}{c}-0.04^{* * *} \\
(0.00)\end{array}$ & $\begin{array}{c}-0.02^{* * *} \\
(0.00)\end{array}$ \\
\hline Validity & $\begin{array}{c}0.47^{* * *} \\
(0.03)\end{array}$ & - & - & - & - & - \\
\hline $\mathrm{SD}_{\text {Validity }}$ & $\begin{array}{c}0.73^{* * *} \\
(0.04)\end{array}$ & - & - & - & - & - \\
\hline Kilometers & - & $\begin{array}{c}0.01^{* * *} \\
(0.00)\end{array}$ & - & - & - & - \\
\hline $\mathrm{SD}_{\text {Kilometers }}$ & - & $\begin{array}{c}0.03^{* * *} \\
(0.00)\end{array}$ & - & - & - & - \\
\hline Hours & - & - & $\begin{array}{c}0.11^{* * *} \\
(0.03)\end{array}$ & $\begin{array}{c}0.09^{* * *} \\
(0.03)\end{array}$ & - & - \\
\hline $\mathrm{SD}_{\text {Hours }}$ & - & - & $\begin{array}{c}0.53^{* * *} \\
(0.04)\end{array}$ & $\begin{array}{c}0.47^{* * *} \\
(0.05)\end{array}$ & - & - \\
\hline Days & - & - & - & - & $\begin{array}{c}0.11^{* * *} \\
(0.02)\end{array}$ & - \\
\hline $\mathrm{SD}_{\text {Days }}$ & - & - & - & - & $\begin{array}{c}0.26^{* * *} \\
(0.04)\end{array}$ & - \\
\hline Minutes & - & - & - & - & - & $\begin{array}{c}-0.02^{* * *} \\
(0.00)\end{array}$ \\
\hline $\mathrm{SD}_{\text {Minutes }}$ & - & - & - & - & - & $\begin{array}{c}0.04^{* * *} \\
(0.00)\end{array}$ \\
\hline Opt-out & $\begin{array}{c}0.36^{* * *} \\
(0.26)\end{array}$ & $\begin{array}{c}1.22^{* * *} \\
(0.21)\end{array}$ & $\begin{array}{c}2.20^{* * *} \\
(0.51)\end{array}$ & $\begin{array}{c}2.78^{* * *} \\
(0.27)\end{array}$ & $\begin{array}{c}2.19^{* * *} \\
(0.74)\end{array}$ & $\begin{array}{c}0.98^{* * *} \\
(0.20)\end{array}$ \\
\hline $\mathrm{SD}_{\text {opt-out }}$ & $\begin{array}{c}4.33^{* * *} \\
(0.27)\end{array}$ & $\begin{array}{c}4.77^{* * *} \\
(0.30)\end{array}$ & $\begin{array}{c}6.12^{* * *} \\
(0.39)\end{array}$ & $\begin{array}{c}5.91^{* * *} \\
(0.37)\end{array}$ & $\begin{array}{c}6.19^{* * *} \\
(0.61)\end{array}$ & $\begin{array}{c}4.66^{* * *} \\
(0.22)\end{array}$ \\
\hline \# of parameters & 5 & 5 & 5 & 5 & 5 & 5 \\
\hline \# of respondents & 974 & 851 & 991 & 990 & 851 & 988 \\
\hline \# of choice obs. & 17532 & 8510 & 11892 & 11880 & 10212 & 11856 \\
\hline \# of draws & 1000 & 1000 & 1000 & 1000 & 1000 & 1000 \\
\hline LL(null) & -19260 & -9349 & -13064 & 13051 & -11219 & -13025 \\
\hline LL(final) & -11986 & -3520 & -4962 & -3901 & -4473 & -5484 \\
\hline McFadden R2 & 0.38 & 0.62 & 0.62 & 0.70 & 0.60 & 0.58 \\
\hline $\mathrm{AIC}$ & 23983 & 7050 & 9935 & 7813 & 8957 & 10979 \\
\hline $\mathrm{BIC}$ & 24022 & 7085 & 9972 & 7849 & 8993 & 11016 \\
\hline Opt-out rate & $43.4 \%$ & $72.1 \%$ & $65.0 \%$ & $76.0 \%$ & $66.2 \%$ & $62.5 \%$ \\
\hline Opt-out all & $8.4 \%$ & $50.8 \%$ & $48.9 \%$ & $55.3 \%$ & $52.8 \%$ & $42.4 \%$ \\
\hline
\end{tabular}


Table 5: Mixel logit model for transportation service bundles. "Opt-out rate" at the bottom of the table designates the opt-out rate over all choice tasks of the experiment, "opt-out all" the share of individuals who have opted out at all choice tasks.

\begin{tabular}{|c|c|c|}
\hline Attribute & Coef. & $\mathrm{SE}$ \\
\hline Cost & $-0.00^{* * *}$ & $(0.00)$ \\
\hline App & $0.46^{* * *}$ & $(0.06)$ \\
\hline $\mathrm{SD}_{\mathrm{App}}$ & $0.41^{* * *}$ & $(0.13)$ \\
\hline PT Validity & $0.53^{* * *}$ & $(0.03)$ \\
\hline $\mathrm{SD}_{\mathrm{PT}}$ Validity & $0.43^{* * *}$ & $(0.02)$ \\
\hline Car-sharing & $0.01^{* * *}$ & $(0.00)$ \\
\hline $\mathrm{SD}_{\text {Carsharing }}$ & 0.00 & $(0.00)$ \\
\hline Bicycle-sharing & $-0.07^{* *}$ & $(0.03)$ \\
\hline $\mathrm{SD}_{\text {Bicycle-Sharing }}$ & $0.03^{* *}$ & $(0.02)$ \\
\hline E-bike-sharing & $-0.08^{* * *}$ & $(0.02)$ \\
\hline $\mathrm{SD}_{\mathrm{E}-\text { Bike Sharing }}$ & 0.04 & $(0.04)$ \\
\hline Park and Ride & $0.03^{* * *}$ & $(0.01)$ \\
\hline $\mathrm{SD}_{\text {Park and Ride }}$ & 0.02 & $(0.02)$ \\
\hline Taxi & $-0.01^{* * *}$ & $(0.00)$ \\
\hline $\mathrm{SD}_{\text {Taxi }}$ & 0.00 & $(0.01)$ \\
\hline Opt-out & $3.41^{* * *}$ & $(0.26)$ \\
\hline $\mathrm{SD}_{\text {Opt-out }}$ & $4.30^{* * *}$ & $(0.21)$ \\
\hline \# of parameters & \multicolumn{2}{|l|}{17} \\
\hline \# of respondents & \multicolumn{2}{|l|}{998} \\
\hline \# of choice obs. & \multicolumn{2}{|l|}{17879} \\
\hline \# of draws & \multicolumn{2}{|l|}{1000} \\
\hline LL(null) & \multicolumn{2}{|c|}{-19642} \\
\hline LL(final) & \multicolumn{2}{|c|}{-7539} \\
\hline McFadden R2 & \multicolumn{2}{|l|}{0.62} \\
\hline $\mathrm{AIC}$ & \multicolumn{2}{|l|}{15113} \\
\hline $\mathrm{BIC}$ & \multicolumn{2}{|c|}{15246} \\
\hline Opt-out rate & \multicolumn{2}{|c|}{$72.14 \%$} \\
\hline Opt-out all & \multicolumn{2}{|c|}{$31.8 \%$} \\
\hline
\end{tabular}




\subsection{WTP Estimation and Comparison}

Table 6 shows the WTP values for the stand-alone services and for the same services in a pure bundle. WTP1 is the mean value of the full WTP distribution, but for WTP2 only the positive values of the WTP distribution were considered (WTP2 is an alternative way of calculating the WTP and is provided to increase the robustness of the results). Public transportation, car-sharing and park and ride were valuated higher in a bundle than as standalone services. Bicycle-sharing, e-bike-sharing and taxi were valuated lower. The average WTP for taxi services was negative, indicating that the average consumer did not wish to purchase a monthly taxi subscription (neither as stand-alone service, nor bundled with other services). The sum of the valuations were CHF 51.6 and CHF 102.2 (WTP1 and WTP2, respectively) for the stand-alone services and CHF 93.7 and 155.9 for the bundled services. The WTP for the smartphone application that integrates all services into a journey planner and acts as the ticketing and payment system was valuated at CHF 104 and CHF 127 (WTP1 and WTP2, respectively).

Figure 2 shows the density functions of the WTP distributions for the stand-alone services and the bundled services. The plots indicate that for the MaaS bundles, bicycle-sharing, e-bike-sharing and taxi are not suitable because only a small fraction of WTP values are positive. Table 7 shows the share of positive WTP values. The smartphone app, public transportation, car-sharing and park and ride exhibit a high share of positive WTP values, while the WTPs for bicycle-sharing, e-bike-sharing and the taxi service are mostly negative.

Table 6: WTP comparison: stand-alone services versus bundled services [CHF/p.m.].

\begin{tabular}{l|cc|cc} 
& \multicolumn{2}{|c|}{ Stand-alone services } & \multicolumn{2}{c}{ Pure bundle } \\
Service & WTP1 & WTP2 & WTP1 & WTP2 \\
\hline Smartphone App & - & - & 103.9 & 127 \\
Public Transportation & 46 & 77.4 & 120.2 & 139.7 \\
Car-Sharing & 0.5 & 1.2 & 2.3 & 2.3 \\
Park and Ride & 2.9 & 6.7 & 7.6 & 7.9 \\
Bicycle-Sharing & 0.8 & 3.4 & -15.2 & $(2.6)$ \\
E-Bike-Sharing & 2.6 & 11.9 & -18.8 & $(3.3)$ \\
Taxi & -1.2 & 1.6 & -2.4 & $(0.1)$ \\
\hline
\end{tabular}


Table 7: Share of positive WTP values for stand-alone services and bundles.

\begin{tabular}{l|c|c} 
& Stand-alone services & Pure bundle \\
Service & \multicolumn{2}{|c}{} \\
\hline Smartphone App & $73.7 \%$ & $86.5 \%$ \\
Public Transportation & $66.9 \%$ & $89.6 \%$ \\
Car-Sharing & $67.9 \%$ & $100 \%$ \\
Park and Ride & $59.6 \%$ & $97.1 \%$ \\
Bicycle-Sharing & $59.7 \%$ & $1.8 \%$ \\
E-Bike-Sharing & $32.6 \%$ & $1.9 \%$ \\
Taxi & & $0 \%$ \\
\hline
\end{tabular}



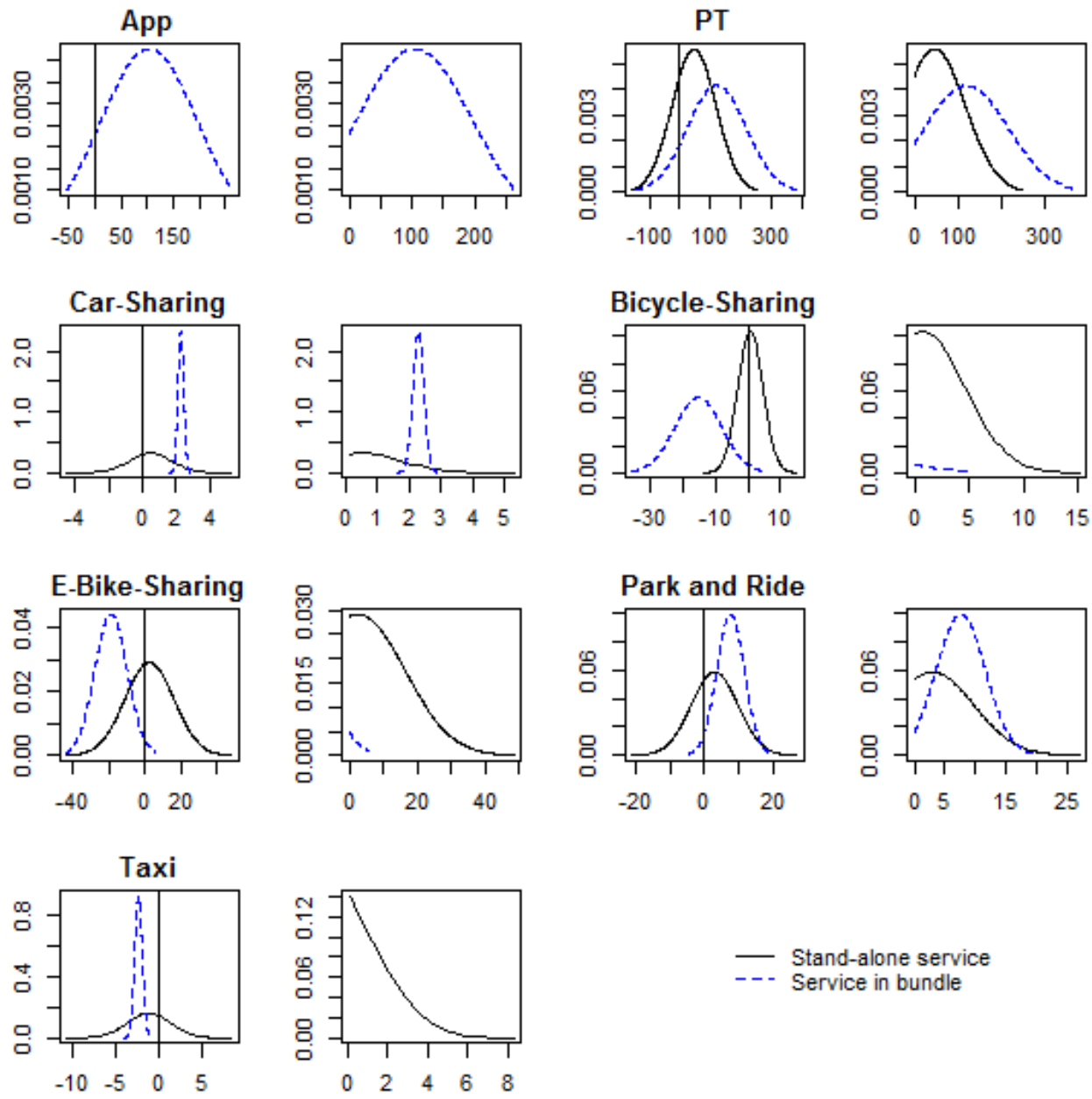

- - Stand-alone service

Figure 2: WTP distributions of bundled transportation services. 


\section{Discussion}

The results of the WTP estimation indicated that the sum of the valuations of the services were higher in bundles than as stand-alone services. This is mainly due to the significantly higher valuation of public transportation in the bundles. Car-sharing and park and ride were also valuated higher in bundles than as stand-alone services. However, the higher overall WTP for bundled services can only partly be attributed to the utility of integrating the services via a mobility platform. As mentioned in section 2.2, similar behaviour has been observed for bundles before: customers tend to purchase more with bundling, an observation which is illuminated by prospect theory and mental accounting (Drumwright, 1992). A similar explanation is the flat-rate bias, which is the observation that some people tend to prefer flat-rates, even though they could save money with a pay-per-use tariff. It is attributed to four effects: a) the insurance effect (i.e. the avoidance of variation in the billing rate), b) the taxi meter effect (i.e. the observation that customers enjoy their usage more with a flat-rate than on pay-per-use traiff), c) the convenience effect (i.e. avoiding the inconvenience of choosing between services) and d) the overestimation effect (i.e. an overestimation of demand) (Lambrecht and Skiera, 2006). The insurance effect and the taxi meter effect are closely related to the explanation of avoiding multiple losses. Wirtz et al. (2015) show that for public transportation, the flat-rate bias can mostly be attributed to the insurance and the convenience effect, which could also be the case for MaaS bundles. Thus, the effects of the flat-rate bias and its role in the higher valuation could be the subject of future research.

The valuation of bicycle-sharing, e-bike-sharing and taxi services were lower in a bundle and the WTP1 values for these services in bundles were even negative. The negative WTP values are a result of the assumption that coefficients are normally distributed. However, the negative coefficients are not necessarily behaviorally unreasonable. If a service provides no utility to a consumer but is part of a bundle, consumers may perceive the price of the bundle as too high, and may even subtract the valuation of the service from the price of the bundle. Thus, a larger extent of service that provides no utility may be perceived as negative. Not all study participants will exhibit such choice behavior. However, if some do, this could be an explanation for the negative signs. Furthermore, bicycle-sharing, e-bike-sharing, and taxi were all services with a very low market share. It is therefore likely that these services indeed only provide limited utility for the majority of users in 
the sample. This could be due to individual preferences, an inability to use the services or due to limited availability in the main activity space of the consumers.

The significant standard deviations indicate the presence of taste heterogeneity. This was expected, as previous literature has shown that MaaS bundles appeal to distinct user groups and purchase likelihood can, to some extent, be explained by household and socio-demographic characteristics $(\mathrm{Ho}$ et al., 2018; Matyas and Kamargianni, 2018). Thus, the effect of household and socio-demographic characteristics will be the subject of future analyses.

In the bundle model, bicycle-sharing, e-bike-sharing and the taxi subscription had a negative effect on the choice of the bundles. This is consistent with previous results by Matyas and Kamargianni (2018), who also observed negative coefficients for these modes. However, contrary to Matyas and Kamargianni (2018), a negative coefficient for car-sharing was not observed in this study. This is consistent with Ho et al. (2018), who also did not observe negative coefficients for car-sharing hours. These differences could be due to different descriptions of the services in the experiments or due to differences in the services themselves.

Consequently, offering pure bundles that include subscriptions to lowshare transportation modes may not be an optimal strategy for mobility providers. As an alternative strategy, a bundle of only public transportation, car-sharing and park and ride could be offered and the smartphone application that integrates the services could be designed such that low-share transportation modes can be purchased on a pay-per-use basis. By bundling products in such a way, the higher WTP for public transportation in bundles could still be exploited. For consumers that choose the bundle, the advantage is guaranteed access to the bundled services without the burden of thinking of the loss each time a service is consumed. The notion that multiple losses are perceived as more negative than a single loss is illuminated by prospect theory and mental accounting (Drumwright, 1992; Gaeth et al., 1990; Yadav, 1994). The higher WTP of consumers for bundled services could therefore be rooted in avoiding multiple losses. This would be interesting to test in future research on individuals with a higher income, and thus a lower price sensitivity.

The WTP for the smartphone app is comparatively high, even for the Swiss price level. Two conceivable reasons for this are the features of the app and the fact that participants attached too much weight to the app compared to the other attributes. The description of the app included the 
following features: ICT and price integration of all services, ticket integration, a comprehensive multimodal journey planner and the analysis of travel behavior in the background to provide suggestions to optimize personal travel (e.g. in terms of cost). The app was also described as being able to show the positions of shared vehicles and the occupancy of parking spots. This comprehensive set of features that is not yet part of any journey planner in Switzerland could be the reason for the high WTP. However, it cannot be excluded that participants simply attached too much weight to the attribute due to the design of the experiment or because it was the only attribute participants did not have experience with (as all other services of the bundle exist in the real market in a similar form). Furthermore, the high WTP for the smartphone app could also be the result of an omitted-variable bias if unobserved factors are correlated with the effect of the app in the bundle.

The overall high WTP for bundles may not be unreasonable and was observed in Switzerland before. In an experiment, the national train company (SBB) offered a mobility package called "SBB Greenclass" (a price bundle) $]^{7}$ (Becker et al., 2018). Greenclass included a 1st class GA travelcard, a BMW i3, park and ride, car-sharing, bicycle-sharing, and vouchers for taxi journeys (total value of CHF 250). The price for SBB Greenclass for a subscription period of one year was CHF 1310 per month and it was directed at high income customers. The stand-alone services cost CHF 1389 per month without the parking subscription (the price of which highly depends on the location). It would cost CHF 599 for an equivalent BMW i3 subscription from a different provider, CHF 525 for the 1st class GA travelcard, CHF 15 for an equivalent car-sharing and bicycle-sharing subscription and CHF 250 for the taxi vouchers. There was no significant integration of the services, thus SBB Greenclass was an example of price bundling. Although the price was slightly lower than the sum of the stand-alone prices, the individual services could mostly not have been consumed at the same time (thus for many customers the price may have been too high relative to the ability to utilize the services). Nevertheless, the trial of SBB Greenclass was considered a success, which provides evidence that there are customer groups with a significant WTP for transportation service bundles.

${ }^{7}$ Prices for the current offer that are slightly different than in the reference given above can be found here: www.sbb.ch/en/travelcards-and-tickets/railpasses/ greenclass.html, last accessed: July 2018. 
Traditional public transportation season tickets are already bundles if they include several public transportation services. For example, the GA travel card in Switzerland is valid for passenger boats, as well as funicular railways, buses, trams and trains and existing journey planners integrate these services. In Switzerland and in many other places, ticket, price and ICT integration is already a reality for collective public transportation. The difference to MaaS schemes is that MaaS also integrates personal transportation services that are available to the public (i.e. taxi, car-sharing, bicycle-sharing etc.), which necessitates more advanced ICT solutions. Supply of personal transportation services is more distributed, and availability cannot readily be predicted by the customer. ICT systems provide utility by filling the information gap and by assisting coordination between customers and mobility service providers.

In a competitive market, in which transportation services can also be purchased as stand-alone services, a positive valuation of bundling and service integration is a necessary condition for the success of bundles. For MaaS bundles, the positive valuation of bundling could stem from two sources: a) the utility provided by the mobility platform, which simplifies inter- and multimodality (service integration) and b) from the flat-rate bias (if pricing is subscription-based). The results of the experiment indicated that the valuation of bundling is positive. As a consequence, transportation service bundles do not necessarily have to be priced lower than the sum of the included services (which was the case for SBB Greenclass). Pricing the bundle lower is an option if services overlap and if they cannot be used at the time (e.g. if the services in the bundle cannot be used by more than one person). The discount that can be offered on the sum of the individual services depends on customers' average ability to utilize the services. 


\section{Conclusion}

"Mobility as a Service" concepts can be seen as a special case of service bundling that is achieved through a mobility platform. Literature on product and service bundling provided concise terminology and bundle classification methodology that was used in the discussion of MaaS bundles.

In this paper, the WTP differences between (subscription-based) standalone and bundled services were investigated. The results indicated that the WTP for public transportation, car-sharing and park and ride services were higher in bundles. Bicycle-sharing, e-bike-sharing and taxi services were valuated lower in bundles compared to stand-alone services. The results have implications for mobility providers that seek to offer transportation service bundles. Offering pure bundles that include low-share transportation modes (i.e. (e-)bike-sharing and taxi services), which may not be perceived directly as complementary to public transportation, may not be effective. Instead, low-share transportation modes could be included on a pay-per-use basis in order to not decrease the overall attractiveness of the bundle. The results also indicate that consumers exhibit a comparatively high WTP at CHF 104 - 127 for a smartphone app that integrates the services, manages ticketing and payment and makes suggestions to optimize personal travel. However, the high valuation of the smartphone app may also be caused by the way it is presented in the experiment and may be affected by the general familiarity of the subjects with apps for transportation services. Furthermore, it is possible that an omitted-variable bias caused an inflation of the smartphone app coefficient, which led to the high WTP value. Future studies could investigate the sensitivity of the WTP with respect to different app features and their presentation. The aforementioned SBB Greenclass experiment may have altered the perception of transportation service bundles for some subject in Switzerland. Thus, it would also be important to conduct similar experiments in different geographical areas to increase the robustness of the results.

The high valuation of the bundled services compared to stand-alone services and the valuation of the smartphone application are most likely not only due to a positive valuation of integration and the mobility platform. An alternative explanation could be a flat-rate bias (which would also be present without integration). Similar to traditional public transportation, the flatrate bias could be caused by the insurance and the convenience effect (Wirtz et al. 2015). Moreover, the overestimation of individual mobility service consumption might play a more important role in MaaS bundles compared 
to traditional public transportation season tickets. These effects were not investigated in this study and could be the subject of future research. If a flat-rate bias is indeed an important cause of the comparatively high valuation of bundling of (subscription-based) services, it would also be interesting to investigate its causes in MaaS bundles.

The effects of mobility behavior, socio-demographic and household characteristics, attitude towards the environment and technological commitment were not yet investigated in this paper and will be subject to future research, as each potentially relates to the purchase likelihood of bundles. Furthermore, future research could also draw from questions raised in the more general bundling literature in marketing and production economics (such as Stremersch and Tellis (2002)). Potential topics include the legality and optimality of bundling strategies, the effect of competition on bundling decisions, and further investigations into consumers' perception of bundles. 


\section{References}

Adams, W., Yellen, J. L., 1976. Commodity Bundling and the Burden of Monopoly. The Quarterly Journal of Economics 90 (3), 475-498.

Armstrong, M., 2013. A more general theory of commodity bundling. Journal of Economic Theory 148 (2), 448-472.

Becker, H., Loder, A., Schmid, B., Jonietz, D., Bucher, D., Axhausen, K., Raubal, M., 2018. Usage patterns and impacts of a mobility flat rate traced with a Smartphone App. In: paper presented at the 15th International Conference on Travel Behavior Research (IATBR 2018). Santa Barbara.

Breidert, C., Hahsler, M., Reutterer, T., 2006. A Review of Methods for Measuring Willingness-to-pay. Innovative Marketing, 1-32.

Cameron, T. A., 1988. A new paradigm for valuing non-market goods using referendum data: Maximum likelihood estimation by censored logistic regression. Journal of Environmental Economics and Management 15 (3), $355-379$.

Cameron, T. A., James, M. D., 1987. Efficient Estimation Methods for "Closed-Ended" Contingent Valuation Surveys. The Review of Economics and Statistics 69 (2), 269-276.

Diekmann, A., Meyer, R., Mühlemann, C., Diem, A., 2009. Schweizer Umweltsurvey 2007 - Analysen und Ergebnisse (Swiss environmental survey - Analyses and results). Tech. rep., BAFU.

Drumwright, M. E., 1992. A Demonstration of Anomalies in Evaluations of Bundling. Marketing Letters 3 (4), 311-321.

Eppen, G. D., Hanson, W. A., Martin, R. K., 1991. Bundling - new products, new markets, low risk. Sloan Management Review v32 (n4), p7(8).

Gaeth, G. J., Levin, I. P., Levin, A. M., 1990. Consumer Evaluation of MultiProduct Bundles: An Information Integration Analysis. Marketing Letters 2 (1), 47-57. 
Guidon, S., Becker, H., Dediu, H., Axhausen, K., 2018. Electric bicyclesharing: a new competitor in the urban transportation market? An empirical analysis of transaction data. Arbeitsberichte Verkehrs- und Raumplanung 1364.

Heikkilä, S., 2014. Mobility as a Service A Proposal for Action for the Public Administration.

Hensher, D. A., 2017. Future bus transport contracts under a mobility as a service (MaaS) regime in the digital age: Are they likely to change? Transportation Research Part A: Policy and Practice 98, 86-96.

Hensher, D. A., Greene, W. H., 2003. The Mixed Logit model: The state of practice. Transportation 30 (2), 133-176.

Ho, C. Q., Hensher, D. A., Mulley, C., Wong, Y. Z., 2018. Potential uptake and willingness-to-pay for Mobility as a Service (MaaS): A stated choice study. Transportation Research Part A: Policy and Practice 117, 302-318.

Hui, W., Yoo, B., Choudhary, V., Yan, K., 2012. Sell by bundle or unit? Pure bundling versus mixed bundling of information goods. Decision Support Systems $53(3), 517-525$.

Jittrapirom, P., Caiati, V., Feneri, A.-M., Ebrahimigharehbaghi, S., González, M. J. A., Narayan, J., 2017. Mobility as a Service: A Critical Review of Definitions, Assessments of Schemes, and Key Challenges. Urban Planning 2 (2), 13.

Kahneman, D., Tversky, A., 1979. Prospect Theory: An Analysis of Decision under Risk. Econometrica 47 (2), 263-291.

Kamargianni, M., Li, W., Matyas, M., Schäfer, A., 2016. A Critical Review of New Mobility Services for Urban Transport. Transportation Research Procedia 14 (0), 3294-3303.

Lambrecht, A., Skiera, B., may 2006. Paying Too Much and Being Happy About It: Existence, Causes, and Consequences of Tariff-Choice Biases. Journal of Marketing Research 43 (2), 212-223.

Matyas, M., Kamargianni, M., 2017. Stated Preference Design for Exploring Demand for "Mobility as a Service" Plans. 5th International Choice Modelling Conference, 16. 
Matyas, M., Kamargianni, M., 2018. The potential of mobility as a service bundles as a mobility management tool. Transportation.

McAfee, R. P., McMillan, J., Whinston, M. D., 1989. Multiproduct Monopoly, Commodity Bundling, and Correlation of Values. The Quarterly Journal of Economics 104 (2), 371-383.

Neyer, F. J., Felber, J., Gebhardt, C., 2016. Kurzskala zur Erfassung von Technikbereitschaft (technology commitment). Zusammenstellung sozialwissenschaftlicher Items und Skalen.

Revelt, D., Train, K., 2000. Customer-Specific Taste Parameters and Mixed Logit: Households' Choice of Electricity Supplier. Economics Working Papers E00-274, University of California at Berkeley.

Rose, J. M., Collins, A. T., Bliemer, M. C., Hensher, D. A., 2014. Ngene.

Sheikhzadeh, M., Elahi, E., 2013. Product bundling: Impacts of product heterogeneity and risk considerations. International Journal of Production Economics 144 (1), 209-222.

Sillano, M., Ortúzar, J. d. D., 2005. Willingness-to-pay estimation with mixed logit models: Some new evidence. Environment and Planning A 37, 525550 .

Sobolewski, M., Kopczewski, T., 2017. Estimating demand for fixed-line telecommunication bundles. Telecommunications Policy 41 (4), 227-241.

Sochor, J., Karlsson, I. C. M., Strömberg, H., 2016. Trying Out Mobility as a Service. Transportation Research Record: Journal of the Transportation Research Board 2542 (2542), 57-64.

Sochor, J., Strömberg, H., Karlsson, I. C. M., 2014. Travellers' motives for adopting a new, innovative travel service: insights from the UbiGo field operational test in Gothenburg, Sweden, 21st World Congress on Intelligent Transportation Systems, Detroit.

Stremersch, S., Tellis, G. J., 2002. Strategic Bundling of Products and Prices: A New Synthesis for Marketing. Journal of Marketing 66 (1), 55-72. 
Swiss Federal Statistical Office (BFS), 2017. Mobilität in der Schweiz - Ergebnisse des Mikrozensus Mobilität und Verkehr 2015. Tech. rep., Swiss Federal Statistical Office (BFS), Neuchatel.

Thaler, R., 1985. Mental Accounting and Consumer Choice. Marketing Science 4 (3), 199-214.

Train, K., 2009. Discrete Choice Methods with Simulation. Cambridge University Press.

Train, K., Weeks, M., 2005. Discrete Choice Models in Preference Space and Willingness-to-Pay Space. Springer Netherlands, Dordrecht, pp. 1-16.

Transport Systems Catapult, 2016. Expolring the opportunities for Mobility as a Service in the UK (July).

Vamosiu, A., 2018. Optimal bundling under imperfect competition. International Journal of Production Economics 195 (September 2017), 45-53.

Walker, J. L., Wang, Y., Thorhauge, M., Ben-Akiva, M., 2018. D-efficient or deficient? A robustness analysis of stated choice experimental designs. Theory and Decision 84 (2), 215-238.

Wirtz, M., Vortisch. P., Chlond, B., 2015. Flatrate Bias in Public Transportation: Magnitude and Reasoning. In: 94th Annual Meeting of the Transportation Research Board, Washington D.C., Washington/USA, January 11-15, 2015.

Yadav, M. S., 1994. How Buyers Evaluate Product Bundles: A Model of Anchoring and Adjustment. Journal of Consumer Research 21 (2), 342353.

Yan, R., Myers, C., Wang, J., Ghose, S., 2014. Bundling products to success: The influence of complementarity and advertising. Journal of Retailing and Consumer Services 21, 48-53. 


\section{Appendix A. DCEs: introductory information for participants}

Each experiment was introduced with an introductory text. The following subsections contain the translated texts.

Appendix A.1. Stand-alone service: general introduction

Please read the following information carefully.

You will be presented with two different mobility services (Option 1 and Option 2). Please decide whether you would purchase the service at the given price or not (i.e. decline).

Remarks:

- Please try to decide the same way as you would in the real world. Decline offers that you would not purchase.

- Assume that you could only purchase the service at the given price and that there would be no other way to purchase the service.

Tip:

- If you are using a smartphone to complete the survey, please use it in landscape mode.

Appendix A.2. Stand-alone service: public transportation

Possible choices:

- Validity: ZVV area (1-2 zones, 3 zones, 4 zones, 5 zones, all zones) or the whole country (GA travel card).

- Second class ticket

Remarks:

- The zones for the cities of Winterthur (120) and Zurich (110) count as two zones.

- In case you already possess a public transportation season ticket, assume that it expired and that the offer is to renew it.

(Figure: Map of PT zones) 
Appendix A.3. Stand-alone service: car-sharing

The car-sharing season ticket provides access to a car-sharing service. The service allows you to access 3000 vehicles at 1500 locations in the whole country. The vehicles can be booked in advance. The service includes a credit of 50, 75, 125 or 150 kilometers per month.

Possible choices:

- Credit: 50, 75, 125 or 150 kilometers per month.

Remark:

- In case you already possess a car-sharing subscription, assume that it has expired and that the offer is to renew it.

Appendix A.4. Stand-alone service: park and ride

A subscription for all park and rail parking spots at SBB train stations. The service includes access to 500 parking spots in the whole country and allows for parking at train stations to transfer to the train. The stations Zurich HB, Zurich Oerlikon and Winterthur are not included.

Possible choices:

- Credit: 4, 7 or 14 days per month.

Appendix A.5. Stand-alone service: bicycle-sharing

A subscription for bicycle-sharing services in the whole country with 2000 bicycles in the canton of Zurich. The service includes a monthly credit. Bicycles can be left anywhere on public ground and are repositioned several times per week by the operator, such that they are located at central locations.

Possible choices:

- Credit: 3, 5, 7 or 10 hours per month. 
Appendix A.6. Stand-alone service: e-bike-sharing

A subscription for e-bike-sharing services in the whole country with 400 bicycles in the canton of Zurich. The service includes a monthly credit. Bicycles can be left anywhere on public ground and are repositioned several times per week by the operator such that they are located at central locations.

Possible choices:

- Credit: 3, 5, 7 or 10 hours per month.

Appendix A.7. Stand-alone service: electric bicycle-sharing

A monthly credit for taxi services in the whole country (in minutes).

Possible choices:

- Credit: 30, 60, 120 minutes per month.

Appendix A.8. Service bundles

Please read the following information carefully. You will be presented with two bundles of mobility services. Please decide whether you would buy the bundle at the given price or not. If you are already using one of the services that is included in the bundles, please assume that you would be reimbursed for that service.

The following services are included in the bundles:

Possible choices:

- Public transportation: ZVV area (1-2 zones, 3 zones, 4 zones, 5 zones, all zones) or the whole country (GA travel card).

- Car-sharing: The car-sharing season ticket provides access to a carsharing service. The service includes a credit of 50, 125 kilometers per month. The service allows you to access 3000 vehicles at 1500 locations in the whole country. 
- Bicycle-sharing: A subscription for bicycle-sharing services in the whole country with 2000 bicycles in the canton of Zurich. The service includes a monthly credit of 3 or 5 hours per month. Bicycles can be left anywhere on public ground and are repositioned several times per week by the operator such that they are located at central locations.

- E-bike-sharing: A subscription for e-bike-sharing services in the whole country with 400 bicycles in the canton of Zurich. The service includes a monthly credit of 3 or 5 hours per month. Bicycles can be left anywhere on public ground and are repositioned several times per week by the operator such that they are located at central locations.

- Parking spots at train stations (park and ride): A subscription for all park and rail parking spots at SBB train stations. The service includes access to 500 parking spots in the whole country and allows for parking at train stations to transfer to the train. The service includes 4,7 or 14 days of parking.

- Taxi subscription: A taxi credit for 30 or 60 minutes for taxi trips in the whole country.

- Smartphone app: The app provides a journey planner (similar to Google maps) that combines the services optimally for each journey. Carsharing, bicycle-sharing and parking spots are displayed on a map (incl. availability and the possibility to book them). Your mobility behavior is analyzed in the background and you are presented with suggestions to reach your destinations faster or at a lower cost. You can also indicate personal preferences, such as walking a prespecified distance by foot or with a bicycle, per week. Payment is managed by the app. Tickets can be displayed by the app. You also receive a plastic card as a ticket.

Remarks:

- Please try to decide the same way as you would in the real world. Decline offers that you would not purchase.

- Assume that you could still buy the services in the usual way. 